“C 2019 IEEE. Personal use of this material is permitted. Permission from IEEE must be obtained for all other uses, in any current or future media, including reprinting/republishing this material for advertising or promotional purposes, creating new collective works, for resale or redistribution to servers or lists, or reuse of any copyrighted component of this work in other works." 


\section{Application of Design Science Research to Design a Modelling Approach for Procurement of Infrastructure Systems}

\author{
Farid Shirvani \\ SMART Infrastructure Facility \\ University of Wollongong \\ Wollongong, Australia \\ farids@uow.edu.au \\ Peter Campbell \\ SMART Infrastructure Facility \\ University of Wollongong \\ Wollongong, Australia \\ pcampbel@uow.edu.au
}

\author{
Pascal Perez \\ SMART Infrastructure Facility \\ University of Wollongong \\ Wollongong, Australia \\ pascal@uow.edu.au \\ William Scott \\ SMART Infrastructure Facility \\ University of Wollongong \\ Wollongong, Australia \\ wscott@uow.edu.au
}

\author{
Ghassan Beydoun \\ Faculty of Engineering and Information \\ Technology \\ University of Technology Sydney \\ Sydney, Australia \\ ghassan.beydoun@uts.edu.au
}

\begin{abstract}
Model-driven approaches are widely used in managing the complex domains such as infrastructure systems or disaster management. The foundation of conducting a systematic research is designing a methodology that pertinently covers the steps of research from problem definition to solution proposal and then identifying or tailoring a method for developing and validating the solution. This paper explains the application of Design Science for conducting a research which aims at providing a model-driven approach for addressing the complexities of infrastructure procurement projects. So firstly the design science artefacts are adopted for designing the method for this research. Then the steps of this method are explained briefly along with description of how each step is applied in this research. The core of this method is proposing a process for developing and validating the metamodels which is designed based on combination of other metamodeling processes.
\end{abstract}

Keywords- Method Engineering, Design Science, Metamodelling, Modelling Language, Complexity Management

\section{INTRODUCTION}

The procurement of infrastructure systems is a complex domain of information which is very difficult to manage because the knowledge pieces are generated by isolated stakeholders who are also interdependent and affect each other. The model-driven approaches are widely used in managing the complexities of interrelated domains such as procurement projects. Rather than aim for a comprehensive and a complete model, in our previous studies [1] [2] we attempt for developing a metamodel which can pull together the various, disparate and partial models that attempt to describe the procurement domain knowledge systematically. The development of a metamodel requires a systematic process called metamodeling that makes statements about what can be expressed in the valid models of the knowledge domain [3].

This paper employs the Design Science Research to design a method for proposing a model driven approach for the infrastructure procurement. So it provides an adoption of the design science cycles to design a method for conducting a research on proposing a model driven approach for addressing the complexities of procurement domain. The core objectives of this method design are tailoring a metamodeling process for development and validation of metamodels.

A specific type of procurement method called Public Private Partnership (PPP) is chosen to represent the procurement process in this study as it is the most complex, long and costly process and is widely used for infrastructure procurement. This paper is structured as follows: section 2 provides an introduction to design science research and its main cycles and then how it is adopted for the PPP domain. Section 3 explains the first cycle of the design which is identifying and elaborating the problem and specifying a model driven solution to address that problem. Section 4 explains how a metamodeling process is tailored based on collection and combination of other metamodeling processes. Section 5 has three subsections that describes application of the tailored process to develop a metamodel (section 5.1), validate the metamodel (section 5.2) and develop the modelling language based on the metamodel (section 5.3). Section 6 briefly explains how the developed modelling language can be applied in the real projects to demonstrate its applicability. Finally, section 7 provides a summary and draws a conclusion.

\section{DESIGN SCIENCE RESEARCH}

Design activities are central to most applied disciplines. As information systems (IS) consist of inherently mutable and adaptable hardware, software, and human interfaces, they provide many unique and challenging design problems that call for new and creative ideas. Design science, as conceptualised by Simon [4], supports a pragmatic research paradigm where innovative artefacts are created solve realworld problems, so design science research focuses on the IT artefact with a high priority on relevance in the application domain. Fig. 1 borrows the IS research framework provided by [5] and overlays a focus on three inherent research cycles. The Relevance Cycle bridges the contextual environment of the research project with the design science activities. The Rigor Cycle connects the design science activities with the knowledge base of scientific foundations, experience, and expertise that informs the research project. The central Design Cycle iterates 


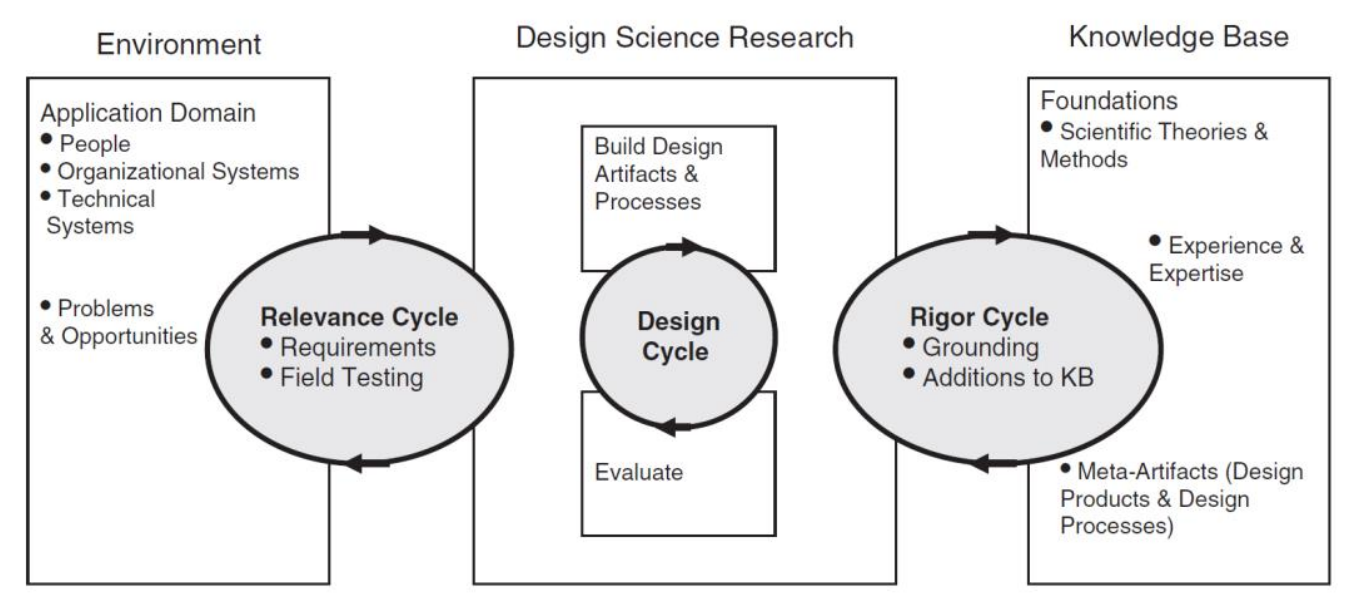

Fig. 1. Design Science Research Cycles

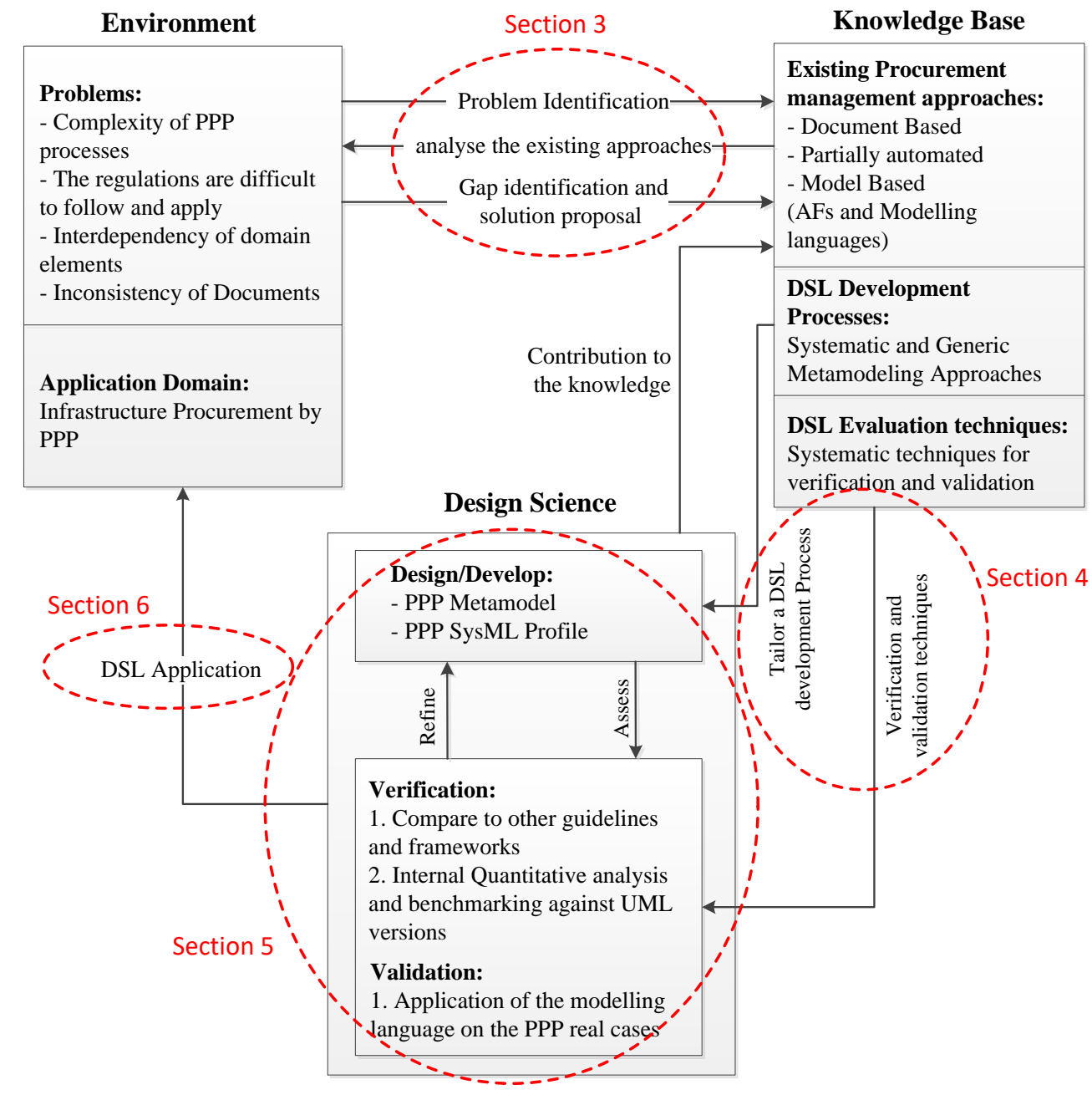

Fig. 2. Research methodology based on design science cycles

between the core activities of building and evaluating the design artefacts and processes of the research. These three cycles must be present and clearly identifiable in a design science research project [5]. The methodology of this research is organised according to the cycles of e design science. Fig. 2 illustrates the research methodology adapted from Fig. 1. The steps of the proposed methodology (which is designed as a loop) are explained in the following sections.
The corresponding sections to the method steps are also noted in Fig. 3 to facilitate navigation through the paper sections and mapping them to the method steps. 


\section{PROBLEM IDENTIFICATION AND SOLUTION PROPOSAL}

\section{A. Problem Identification}

The relevance cycle initiates design science research by reviewing the literature to find the research problems. So a literature review on the PPP domain is carried out to identify the inherent problems and challenges in the PPP projects to be tackled in this research. The main problems with PPP projects are their complex processes and regulations which are difficult to follow, and the constituent elements of PPP projects are highly interdependent such that any change in one part of the project is distributed across the whole project and affects other project elements. The existing procurement management methods are document based i.e. the project documentation and system life cycle steps are paper documents (or an electronic version of paper). Tracing the changes in documents and keeping them consistent is very time consuming and error prone, which means document based methods are not suitable for managing complex projects like PPP procurements.

\section{B. Gap Identification}

The best practices for model based approaches are provided by US DoD (Department of Defense) and NASA and they are based on using the architecture frameworks and modelling languages. UPDM [6] is developed based on two defence acquisition frameworks (DoDAF and MoDAF) that are used as a unified architecture framework which covers the whole enterprise, including the systems and procurement of those systems. However, UPDM does not meet all the concerns of procurement stakeholders so this research proposes to expand the UPDM (which is now reformed to UAF: Unified Architecture Framework) by adding more elements so it will be more capable of generating the procurement aspects of the projects.

\section{Proposing the Solution}

This research proposes a model driven approach which is the development of a metamodel that fully covers the PPP domain and can satisfy stakeholder concerns. The metamodel means it can be used as the abstract syntax of a Domain Specific Language which will be used by domain practitioners to document the project phases as integrated and consistent models. So the solution can be specified as: a Modelling Language which consists of a metamodel as the abstract syntax and a SysML (Systems Modelling Language) profile that is the implementation of the metamodel in the modelling environment. This modelling language will be used by practitioners (procurement stakeholders) to create models (views) of the procurement domain. This metamodel is called the Procurement Metamodel (PMM) and the modelling language is referred to as the Procurement Modelling Language (PML).

\section{DESIGNING A TAILORED METHOD FOR DEVELOPMENT AND VALIDATION OF METAMODEL AND MODELLING LANGUAGE}

A variety of systematic methods to develop, verify, and implement metamodels were reviewed as shown in the first column of TABLE. 1. Each method focuses on a particular artefact of the language, for example, the method provided by [11] can be used to develop and verifying the metamodel (abstract syntax), while Silingas [14] provides a method for developing the SysML based concrete syntax for a given metamodel. To develop and verify the deliverables of this research (PML artefacts) a method needs to be tailored to its context as the development and validation process. For this purpose, the methods provided are critically analysed and the suitability of each method is investigated. So, each method has contributed in to the right part of the customized tailored method. TABLE. 1 indicates the contribution these systematic methods make to the tailored method. The tailored process is shown in Fig. and its application is briefly explained in the following section.

\section{APPLICATION OF THE TAILORED METHOD TO DEVELOP AND VALIDATE THE METAMODEL AND MODELLING LANGUAGE}

\section{A. Developing the First Version of the Procurement Metamodel (PMM 1.0)}

The internal design cycle is the heart of any design science research project. This cycle of research activities iterates between constructing an artefact, its evaluation, and subsequent feedback to further refine the design. The tailored method which is drawn from the rigor cycle is used in this phase to develop and implement the metamodel. As indicated in the process, this method is based on gathering as many guidelines as possible and combining them to achieve a complete metamodel. The development steps are as follows.

TABLE. 1. CONTRIBUTION OF DIFFERENT SYSTEMATIC APPROACHES TO THE TAILORED METHOD

\begin{tabular}{|c|c|}
\hline Source name & Contribution to our method \\
\hline $\begin{array}{l}\text { - An approach for the systematic development of domain-specific languages } \\
\text { [7] }\end{array}$ & $\begin{array}{l}\text { - Identify the type of DSL } \\
\text { - Identify the DSL structure and artefacts }\end{array}$ \\
\hline $\begin{array}{l}\text { - Architecture description template for use with ISO/IEC/IEEE 42010:2011 } \\
\text { [8] } \\
\text { - Initial Report on Guidelines for Architectural Level SoS Modelling } \\
\text { (COMPASS) [9] }\end{array}$ & - $\quad$ Breaking the domain into fragments (Viewpoints) \\
\hline $\begin{array}{l}\text { - FAML: A Generic Metamodel for MAS Development [10] } \\
\text { - Development and validation of a Disaster Management Metamodel } \\
\text { (DMM) [11] } \\
\text { - Design and validation of a metamodel for metacognition support in } \\
\text { artificial intelligent systems [12] }\end{array}$ & - Conceptual definition of each viewpoint \\
\hline - Metamodel-based UML Notations for Domain- specific Languages [13] & - Developing the Concrete Syntax (profile) \\
\hline - Domain Specific Modelling Environment Based on UML Profiles [14] & $\begin{array}{l}\text { - Implementing the Concrete Syntax by Stereotype } \\
\text { definition } \\
\text { - Creating customized SysML diagram frames } \\
\text { - Configuration of the modelling environment }\end{array}$ \\
\hline
\end{tabular}




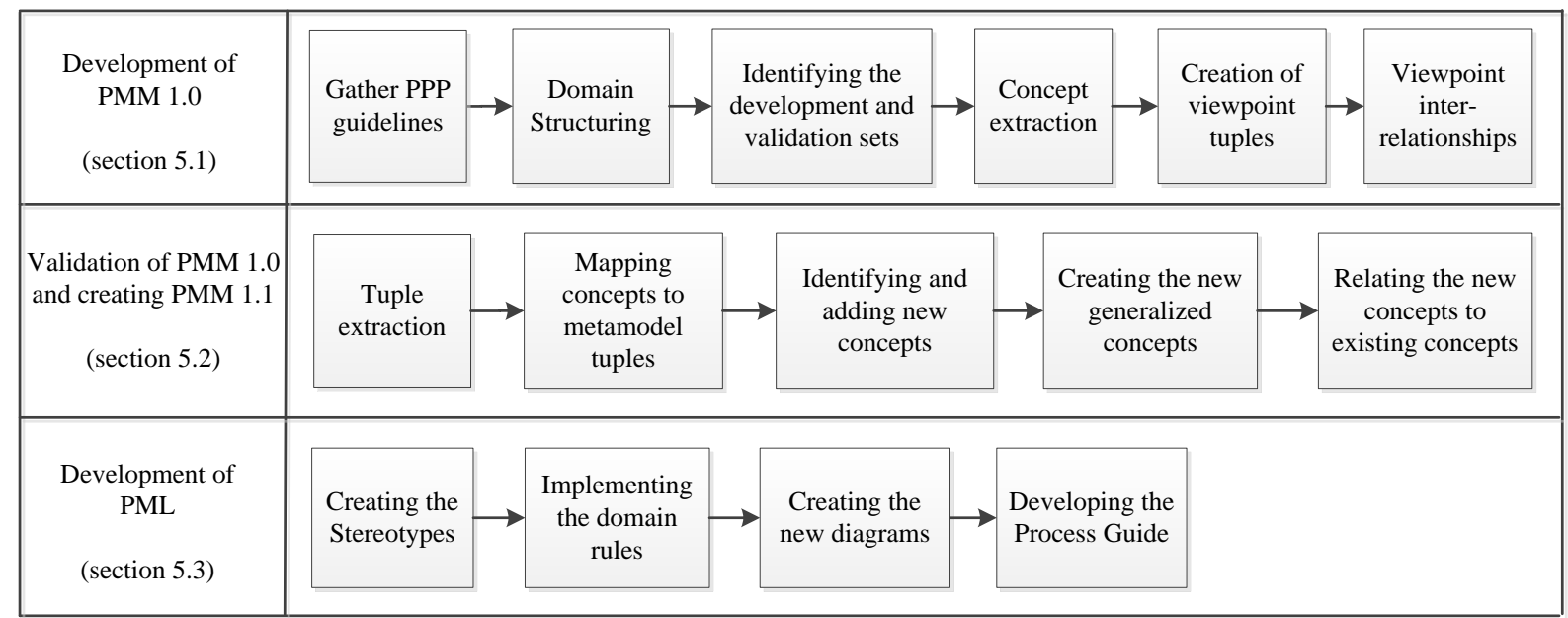

Fig. 3. A tailored process for development and validation of the PMM and PML

Step 1: Knowledge gathering: The PPP guidelines and frameworks are collected from the infrastructure departments of different countries, regulatory agencies, consultancy agencies and PPP expert groups from all around the world. In this step, more than 50 resources are collected which include EPEC Guide to Guidance [15], World Bank PPP reference guide [16], and Concessions for infrastructure - A guide to their design and award [17].

Step 2: Creating the domain breakdown structure: the PPP domain consists of a variety of phases and several steps in each phase which makes it a very wide domain. So before extracting the meaningful information pieces from the PPP guidelines, a structure for breaking down the domain must be created to ensure that the information extracted is organised and focused.

Step 3: Identifying the development and verification sets: the collected sources (guidelines) should be divided into two sets where one can be used to develop the metamodel and the other for the first round of metamodel verification. The sets should be selected such that the guidelines of each set cover every metamodel viewpoint.

Step 4: Extraction of concepts: the guidelines are published in a textual format accompanied by charts and figures. In order to have uniform information, the extracted statements from every guideline are transformed into a tuple format (concept - relationship - concept). TABLE 2 shows the list of contract organizations and their relationships (as the example of domain concepts) that are extracted from two different sources.

Step 5: Creating the finalised tuples: in this step the finalised concepts and relationships are used to create the finalised tuples which constitute the body of a viewpoint (a fragment of the metamodel). Fig. 4 illustrates the contract organization relationships viewpoint as an example of a metamodel viewpoint.

Step 6: Identifying the relationships to other viewpoints: when defining the finalised tuples of each viewpoint, some concepts will have been defined in previous viewpoints, so they can be reused in the viewpoint and the common concept will relate the two viewpoints together. At the end of defining each viewpoint, every concept is checked to see whether it has any relationship to the concepts of other viewpoints.

\section{B. Validation of PMM 1.0 and Developing PMM 1.1}

TABLE 2. EXTRACTED CONCEPTS FOR THE ORGANIZATION RELATIONSHIPS'

\begin{tabular}{|c|c|}
\hline Source & $\begin{array}{c}\text { Extracted Concepts: Contract Organizations } \\
\text { Relationships }\end{array}$ \\
\hline $\begin{array}{lr}\text { World Bank: } & \text { Public- } \\
\text { Private Partnerships } \\
\text { Reference } \quad \text { Guide, } \\
\text { Version 2.0 } \\
\text { (pp 18, 51) }\end{array}$ & 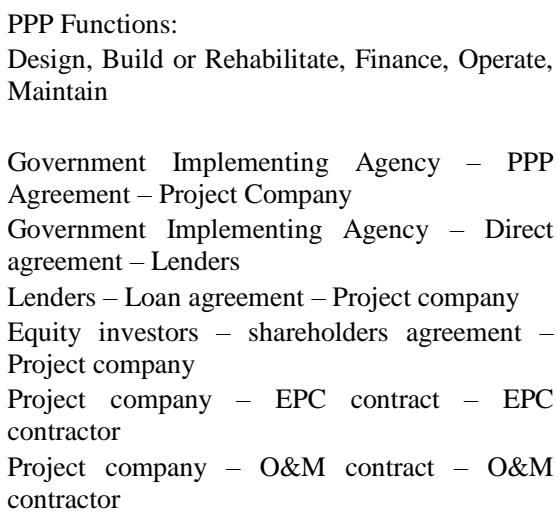 \\
\hline $\begin{array}{l}\text { PPIAF: The Toolkit } \\
\text { for Public-Private } \\
\text { Partnerships in Roads } \\
\text { and Highways } \\
\text { (Module 1, p 51) }\end{array}$ & $\begin{array}{l}\text { PPP Units -- Contracting Authority } \\
\text { Contracting Authority -- Consultancy Contract - } \\
\text { - (Design and Traffic Consultants, Advisors) } \\
\text { Contracting Authority -- Concession Contract -- } \\
\text { O+M Concessionaire } \\
\text { O+M Concessionaire -- Toll collection -- Road } \\
\text { users } \\
\text { O+M Concessionaire -- Consultancy Contract -- } \\
\text { Advisors } \\
\text { O+M Concessionaire -- Bonds -- Insurers } \\
\text { O+M Concessionaire -- Operation and } \\
\text { Maintenance Contract -- Operator } \\
\text { Operator -- sub-contract -- sub-contractors } \\
\text { Operator -- Consultancy contract -- (Technical } \\
\text { Advisor, Design Consultants) } \\
\text { Financing Institutions -- Loan Agreement + } \\
\text { Guarantees -- O+M Concessionaire } \\
\text { Commercial Lenders -- Loan Agreements -- } \\
\text { O+M Concessionaire } \\
\text { Export Credit Agencies -- Guarantee -- O+M } \\
\text { Concessionaire }\end{array}$ \\
\hline
\end{tabular}




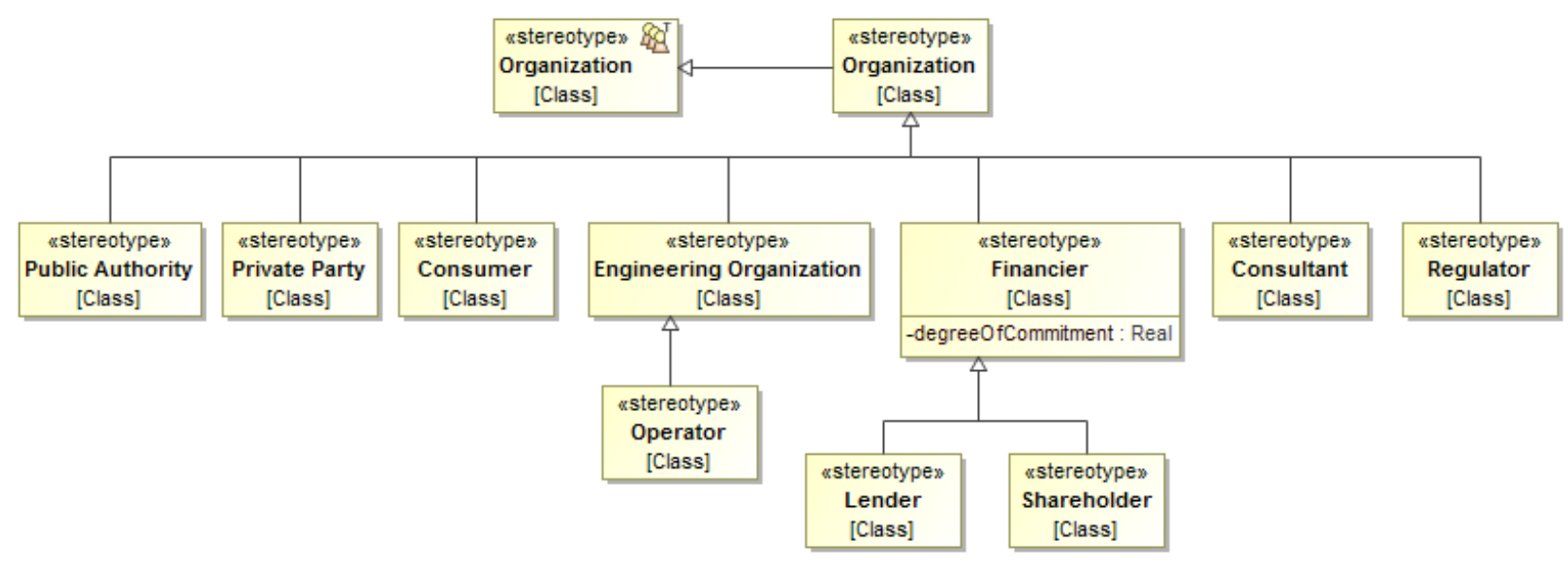

Fig. 4. Typical organizations in a PPP contract

The essence of Information Systems research as design science lies in the scientific evaluation of artefacts." The developed artefacts must be rigorously and thoroughly tested in laboratory and experimental situations before releasing them for field testing along the relevance cycle. This calls for multiple iterations of the design cycle in design science research before contributions are output into the relevance and rigor cycles. The validation used in this study is to compare the metamodel against the guidelines of validation set. This technique ensures the metamodel is complete by identifying and adding any missing concepts. The validation set includes guidelines that contain generic information about PPP processes and provide generic guidance on conducting the processes and developing the required documents. The steps of this phase are as follows:

1. Extraction of tuples from the validation set guidelines

2. Mapping extracted tuples to the metamodel tuples

3. Identifying new concepts for the metamodel

4. Creating new generalised concepts

5. Identifying the relationships of new concepts to the existing concepts

\section{Developing the Procurement Modelling Language (PML)}

The output from the design science research must be returned to the environment for study and evaluation in the application domain. In order to make the metamodel applicable, it must be implemented in a tool to allow practitioners to use it for modelling the procurement projects. The following steps are designed for concretising the metamodel as a modelling language (PML):

Step 1: Implementing the metamodel by stereotypes: the stereotypes are specialised classes with specific attributes which represent the concepts and relationships of the metamodel. In this step the metamodel elements are implemented in the modelling tool.

Step 2: Writing the language rules in Java: the rules and constraints of the domain which is identified in creating the metamodel are written in Java language, so they enforce the rules to the metamodel to ensure the generated models are consistent and well formed.

Step 3: Developing the customised new diagram frames: every viewpoint of the metamodel represents a type of diagram so in this step a diagram frame is created for each viewpoint to allow the modellers to generate a piece of the project model. The frames are similar to UML and SysML diagrams (class diagram, activity diagram, etc.) but they are domain specific because they are designed specifically for the PPP domain.

Step 4: Developing the process guide: in this step the right order of using the diagrams is provided to the users as a modelling process guide.

\section{APPLICATION AND DEMONSTRATION OF THE PML}

As mentioned in the design science cycles (Fig. 2) the created artefact must be applied in the domain of application to assess its usability, so to apply the language in the real domain, some real PPP project documents must first be collected. Projects are collected from different countries and different sectors to ensure the metamodel is assessed over quite a large variety of application domains. Since the project documentation is confidential intellectual property the complete documentation of a project is unlikely to be found even if the documents are partially available, so the other criterion for collecting project documents is to ensure they aggregately cover all the metamodel viewpoints. In order to exemplify the applicability of the PML, a real PPP project is selected (Rail Corp Rolling Stock PPP Project). The organization relationship viewpoint (Fig. 4) is then used to model the contract organizations and their relationships. Fig. 5 illustrates the contractual relationships of the RailCorp Rolling Stock PPP project; then it is modelled by the language, as shown in Fig. 6.

\section{SUMMARY AND CONCLUSION}

The complex domains need to be managed by rigour solutions that are developed through a systematic design process. Procurement of the infrastructure systems is a complex domain to manage as it includes many organizations that are involved in different types of contracts which requires generating large amount of documents that are interdependent and therefore difficult to maintain their consistency. This paper applied the cycles of Design Science Research to systematically analyse the infrastructure procurement domain for identification of its problems and proposing a model driven solution (section 3), tailoring a replicable method by reviewing and combining other methods (section 4), designing, implementing and evaluating 


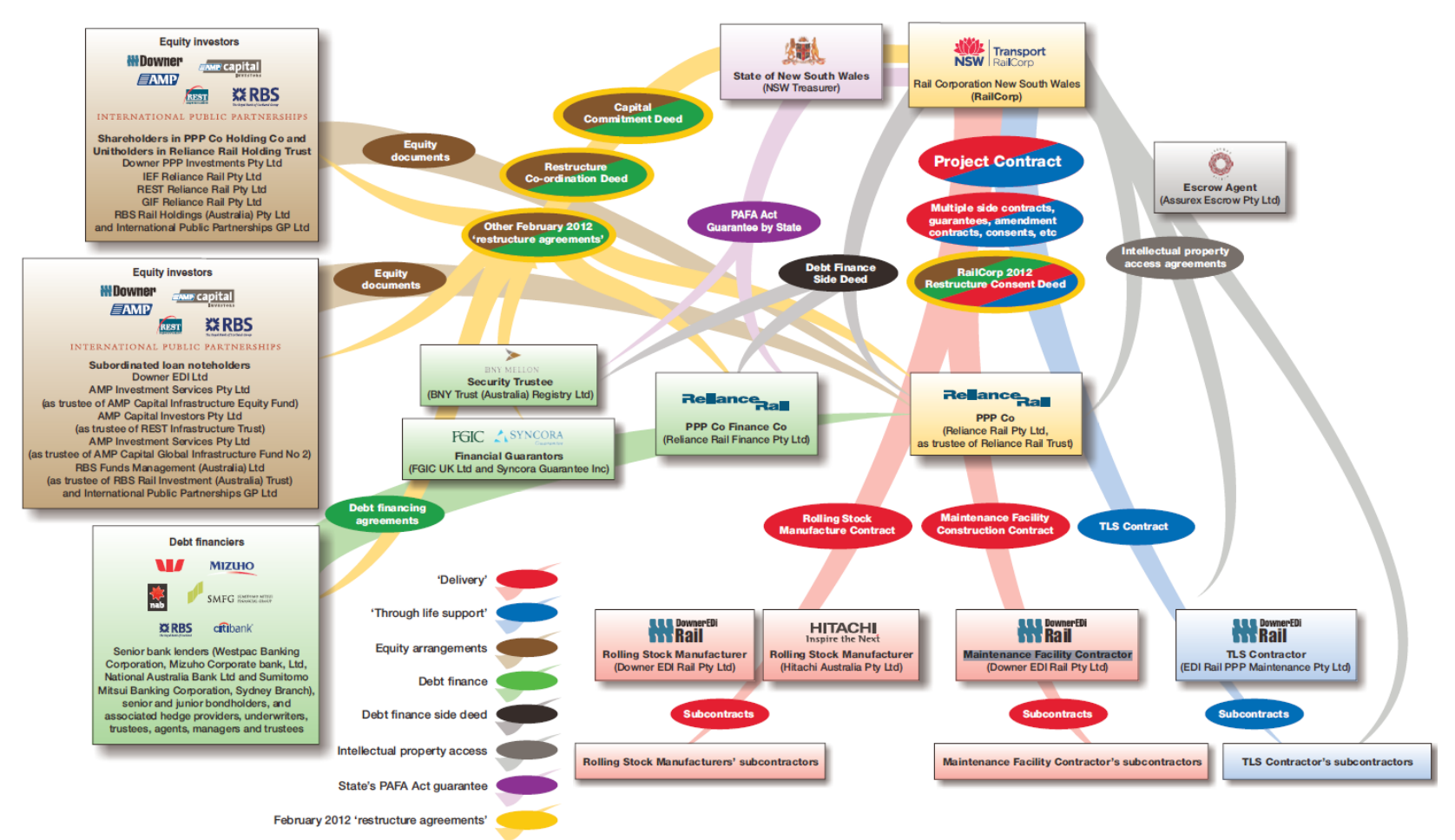

Fig. 5. Contractual relationships of Rail Corp Rolling Stock PPP project

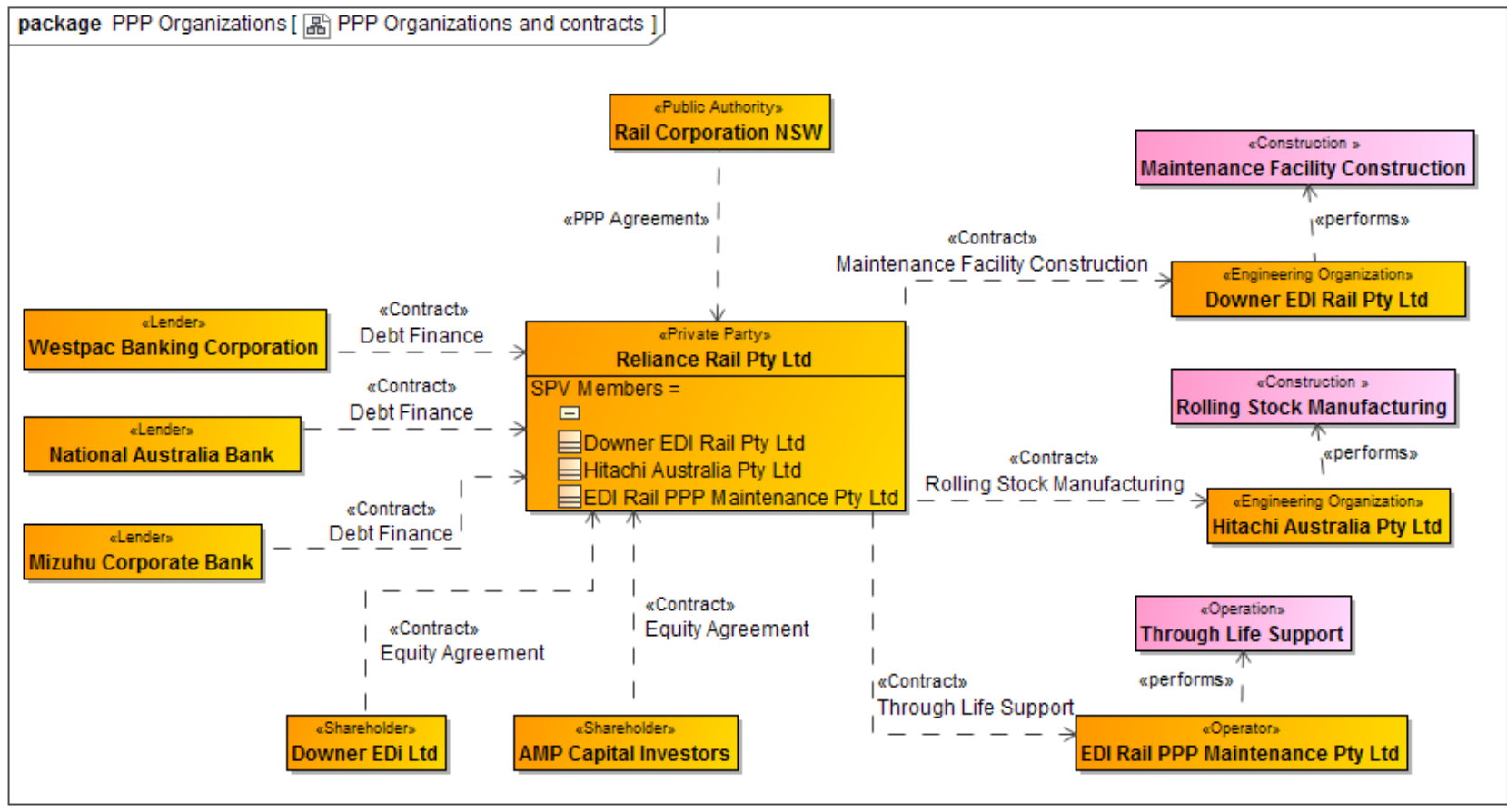

Fig. 6. Organization relationships modelled by the PML

the solution (section 5), and applying the solution in the procurement domain to assess its applicability in the real use cases (section 6). So, one of the main contributions of this research is tailoring a method for developing and validating the metamodels and modelling languages. The tailored method is then used to develop the PMM (Procurement Metamodel) and PML (Procurement Modelling Language) which mean to address the complexities of infrastructure procurement projects through generating consistent and integrated models.

\section{REFERENCES}

[1] F. Shirvani, P. Perez, P. Campbell, and G. Beydoun, "Employing the model based systems engineering methodologies to develop a domain specific language for contracting of infrastructure projects," in Systems Conference (SysCon), 2018 Annual IEEE International, 2018, pp. 1-7.

[2] F. Shirvani, W. Scott, P. Perez, and P. Campbell, "Managing the complexities of infrastructure procurement projects-a model based systems engineering approach," in Systems Evaluation Test and Evaluation Conference 2018: Unlocking the Future Through Systems Engineering: SETE 2018, 2018, p. 502. 
[3] E. Seidewitz, "What Models Mean," IEEE Software, vol. 20, pp. 26 32 September/October 20032003.

[4] H. A. Simon, The sciences of the artificial (3rd ed.): MIT Press, 1996.

[5] A. R. Hevner, S. T. March, J. Park, and S. Ram, "Design science in information systems research," MIS Q., vol. 28, pp. 75-105, 2004.

[6] OMG, "Unified Profile for DoDAF and MODAF (UPDM) V 2.1," 2013.

[7] M. Strembeck and U. Zdun, "An approach for the systematic development of domain-specific languages," Software-Practice \& Experience vol. 39, pp. 1253-1292, 2009.

[8] R. Hilliard, "Architecture description template for use with ISO/IEC/IEEE 42010:2011," Creative Commons Attribution 3.0 Unported License 2012.

[9] J. Holt, C. B. Nielsen, F. O. Hansen, A. Miyazawa, R. Payne, J. Iyoda, et al., "Initial Report on SoS Architectural Models," COMPASS2012.

[10] G. Beydoun, G. Low, B. Henderson-Sellers, H. Mouratidis, J. J. Gomez-Sanz, J. Pavon, et al., "FAML: A Generic Metamodel for MAS Development," IEEE Trans. Softw. Eng., vol. 35, pp. 841-863, 2009.

[11] S. H. Othman, G. Beydoun, "A disaster management metamodel (DMM) validated". In: Kang BH., Richards D. (eds) Knowledge Management and Acquisition for Smart Systems and Services. Springer, Berlin, Heidelberg, pp 11-125, 2011.

[12] M. F. Caro, D. P. Josyula, M. T. Cox, and J. A. Jiménez, "Design and validation of a metamodel for metacognition support in artificial intelligent systems," Biologically Inspired Cognitive Architectures, vol. 9, pp. 82-104, 2014.

[13] A. D. Brucker and J. Doser, "Metamodel-based UML Notations for Domain-specific Languages," presented at the 4th International Workshop on Language Engineering (atem 2007), 2007.

[14] D. Silingas, R. Vitiutinas, A. Armonas, and L. Nemuraite, "DomainSpecific Modeling Environment Based on Uml Profiles," No Magic, http://www.nomagic.com/attachments/article/408/domain-

specific_modeling_environment_based_on_uml_profiles.pdf2011.

[15] E. P. E. Centre, "The Guide to Guidance: How to Prepare, Procure and Deliver PPP Projects," 2012.

[16] W. Bank, "Public-Private Partnerships Reference Guide: Version 2.0," http://api.ning.com/files/Iumatxx0jz3owSB05xZDkmWIE7GTVYA3cXwt4K4s3Uy0NtPPRgPWYO1 ILrWaTUqybQeTXIeuSYUxbPFWlysuyNI5rL6b2Ms/PPPReference Guidev02Web.pdf2014.

[17] M. Kerf;, R. D. Gray;, T. Irwin;, C. Levesque;, R. R. Taylor;, and M. Klein;, "Concessions for infrastructure; A guide to their design and award," Washington, D.C.20433 USA1998. 